\title{
LAS SOCIEDADES ANÓNIMAS CRUZAN LOS ANDES: LOS INVERSORES CHILENOS EN NEUQUÉN AL COMENZAR EL SIGLO XX
}

\author{
Graciela Blanco* \\ Universidad Nacional del Comahue, Neuquén, Argentina, <graciela.blanco47@gmail.com>
}

Resumen. El territorio de Neuquén, en el norte de la Patagonia, atrajo la mirada de diversos inversores privados a partir del avance militar que realizó el Estado nacional sobre los grupos indígenas y de la conquista de las tierras del sur argentino; tierras que fueron ofrecidas a particulares en propiedad o arrendamiento en condiciones muy beneficiosas. Este trabajo analiza la conformación en Chile, en los primeros años del siglo XX, de sociedades anónimas que explicitaban como objetivo central la intención de comprar tierras a ambos lados de la Cordillera de los Andes para la explotación agroganadera y la comercialización, y estudia específicamente el origen, itinerario y organización productiva de una de esas sociedades en Neuquén.

Palabras clave: Inversiones en tierra, sociedades anónimas, organización productiva, norpatagonia.

Abstract. Neuquen territory, in the north of the Patagonia, attracted the look of diverse investors after from the military advance that realized the national State on the indigenous groups and of the conquest of the lands of the Argentine's south, lands that were offered to individuals in property or lease in very beneficial conditions. This work analyzes the conformation in Chile, in the first years of the 20th century, of joint-stock companies that stated explicitly as central aim the intention of buying lands on both sides of the Mountain chain of the Andes for the agricultural and livestock exploitation and the commercialization, and there studies specifically the origin, itinerary and productive organization of one of these companies in Neuquen.

Key words: Investments in land, joint-stock companies, productive organization, North Patagonia.

Fecha de recepción: abril de 2010. Fecha de aceptación: julio de 2010

* Se agradece a los evaluadores anónimos las valiosas acotaciones, interrogantes y sugerencias realizadas a la primera versión de este trabajo.

Am. Lat. Hist. Econ., año 19, núm. 2 (38), mayo-agosto, 2012, pp. 107-130 


\section{INTRODUCCIÓN}

$\mathrm{E}$ n la década de 1880, luego del avance militar sobre los territorios del sur y norte de Argentina ocupados hasta entonces por sociedades indígenas que fueron exterminadas y/o despojadas de sus tierras, el Estado tomó efectivo control sobre esos espacios y procedió a su organización político-administrativa en nueve territorios nacionales, entre ellos el de Neuquén. ${ }^{1}$ Ubicado en el noroeste de la Patagonia, Neuquén reconoce en sus 94078 kilómetros cuadrados de extensión una importante diversidad fisiográfica que se refleja en una disminución del relieve y de las lluvias en dirección oeste-este, con efectos directos sobre la vegetación. La cordillera de los Andes -límite natural con el vecino país de Chile- y la cordillera del Viento imprimen particulares características al oeste y al centro del territorio; la meseta patagónica, en cambio, domina el área oriental. Estas características estuvieron estrechamente relacionadas con los rasgos que adoptó el asentamiento humano y con las actividades productivas desarrolladas en el área, particularmente la ganadería que ha sido históricamente dominante.

El desarrollo de esta actividad en Neuquén, por la calidad de las pasturas y la disponibilidad de agua, fue muy importante en las áreas más próximas al macizo andino, de norte a sur, donde predominó la explotación del ganado bovino. También con inmejorables condiciones para la producción de vacunos y ovinos se ocupó y puso en explotación el sudoeste neuquino, atravesado por importantes cursos de agua. Estas zonas reconocen, previo a la ocupación blanca de las tierras, un aprovechamiento económico por parte de la sociedad indígena que intercambiaba ganado, pieles, cueros y otros subproductos a través de los Andes con los grupos indígenas y con los criollos que habitaban el sur chileno. ${ }^{2}$

El territorio neuquino, como los demás establecidos por la ley de 1884, tuvo hasta su transformación jurídica en provincia -ocurrida a mediados del siglo XX- una organización que lo hacía depender directamente de los gobiernos nacionales, restándole autonomía política, económica y decisoria hasta en las cuestiones mínimas de funcionamiento. Los habitantes de Neuquén se vieron limitados en la posibilidad de ejercer sus derechos políticos a través del voto; no podían elegir autoridades nacionales ni provinciales, sólo definían cargos municipales y titulares de los juzgados de

\footnotetext{
${ }^{1}$ La Ley 1532 de 1884 estableció la creación de los territorios nacionales de Chaco, Formosa y Misiones en el noreste, y los de Neuquén, Río Negro, Chubut, Santa Cruz y Tierra del Fuego en el sur.

${ }^{2}$ Un análisis particularizado de las características del espacio neuquino previo al avance militar y la ocupación blanca del espacio puede verse en Varela y Bisset, "Guerras", 1993, cap. II.
} 
paz cuando estos organismos se constituían. ${ }^{3}$ En ese mismo sentido, las políticas públicas diseñadas para la ocupación y puesta en valor de los nuevos espacios, así como la legislación que puso en marcha el proceso de distribución de tierras públicas a particulares, fueron definidas en los ámbitos de poder ligados al Estado central y ejecutadas desde allí.

Como producto de las diversas leyes y condiciones de entrega de tierras, se produjo la ocupación y puesta en producción ganadera del noroeste y centro-oeste de Neuquén en las últimas dos décadas del siglo XIX, haciéndose extensivo al sur en las décadas siguientes. La prioridad que se dio a esas áreas estuvo directamente vinculada, además de sus posibilidades productivas, con la existencia de un mercado demandante constituido por los centros urbanos y las agroindustrias del sur chileno, que necesitaban importar ganado para el consumo interno y para cubrir las necesidades de las curtiembres, graserías, saladeros y fábricas de velas y jabón allí instaladas. Esta vinculación comercial fue fundamental en las primeras etapas para el desarrollo de la actividad ganadera regional que, alejada de los centros atlánticos hasta la llegada en 1902 del Ferrocarril Sud a la ciudad capital de Neuquén y su posterior extensión a Zapala en el centro del territorio en 1913, encontró por largo tiempo en el mercado chileno las mejores condiciones para colocar la producción. La posibilidad de comunicación y transporte con los mercados bonaerenses a través del ferrocarril, más difícil y costosa, fue lenta y paulatinamente aprovechada por los productores locales más importantes coexistiendo hasta las décadas de 1930 y 1940 una doble vinculación comercial con los mercados del Pacífico y del Atlántico. El primero, absolutamente dominante en los comienzos, fue perdiendo peso en relación con las políticas aduaneras de los gobiernos chileno y argentino, los efectos de la crisis internacional de 1929-1930 y las políticas nacionales tendentes a lograr una industrialización que requería de un mercado interno ampliado y unificado. ${ }^{4}$ Asimismo, la adecuación de algunos productores regionales a los requerimientos de calidad de los mercados de Bahía Blanca y Buenos Aires, a partir de la mestización del ganado y de la incorporación de nuevos métodos de producción, fueron potenciando esa orientación comercial atlántica.

Volviendo a las formas que adoptó la distribución de la tierra pública por parte del Estado nacional, estas mostraron en Neuquén la misma liberalidad que en el resto de los territorios nacionales. La explicitada intención de "poblar" que contenían las diversas leyes sancionadas no se

\footnotetext{
${ }^{3}$ Bandieri, "Neuquén", 2000.

${ }^{4}$ La vinculación comercial de la región con ambos mercados, así como las políticas que provocaron el cierre de la frontera han sido especialmente analizadas en Bandieri, "Neuquén", 1999, y "Estado", 2001, pp. 345-374.
} 
cumplió en la mayoría de los casos, resultando en cambio el mecanismo idóneo para el acaparamiento y la especulación, situación que los gobiernos de principios del siglo XX intentaron revertir sin demasiado éxito para impedir la concentración del recurso. De hecho, el acceso a la tierra no fue fácil para el que no contara con un capital mínimo -o con la posibilidad de conseguirlo vía el crédito- para formar un establecimiento. En el caso neuquino el resultado fue la entrega en donación o a precios muy bajos de extensas superficies -entre 40000 y 80000 hectáreas- a pocos propietarios hacia finales del siglo XIX, en las áreas con mejor aptitud ganadera. De ellos, en su mayoría individuos radicados en Buenos Aires y vinculados a las elites de poder porteñas, sólo unos pocos pusieron las tierras en producción, mientras los restantes especularon con la subdivisión y/o venta en bloque de las mismas cuando se valorizaron por el incremento paulatino de población, la puesta en marcha de la producción y la existencia de mercados demandantes. ${ }^{5}$

La posibilidad de individualizar a través de los expedientes de mensura y otras fuentes catastrales a quienes resultaron beneficiarios de tierras bajo distintas formas de tenencia en función de la legislación vigente, así como el seguimiento de muchas de las transferencias posteriores de las superficies, permitió profundizar y particularizar el estudio de las nuevas explotaciones y sus formas de organización, así como plantear algunas distinciones en relación con el origen y a las estrategias productivas y de inversión puestas en práctica respecto de esas tierras. ${ }^{6}$

Sin duda, para comienzos del siglo Xx el resultado de la política distributiva y de las ventas especulativas que se produjeron a poco de obtenidas las superficies en propiedad en Neuquén -situación que se repite en otras áreas del espacio patagónico-, mostraban un territorio con un intenso proceso de privatización de tierras en el oeste y sur del mismo, áreas en las que predominaron las grandes explotaciones -más de 30000 hectáreas, en las condiciones productivas de esos espacios. Algunos de los nuevos propietarios -tres o cuatro casos- estaban al frente de las empresas que

${ }^{5}$ La Ley 817 de Inmigración y Colonización fue la que mayor impacto tuvo en las tierras transferidas por el Estado nacional a manos privadas a fines del siglo XIX en Neuquén. Un total de 27 concesionarios obtuvieron 1621000 hectáreas para colonizar, aunque en ningún caso introdujeron colonos y en casi todos se convirtieron en propietarios de las superficies concedidas a partir de la aplicación de otra ley de 1891. Sólo cuatro de esos concesionarios explotaron las superficies personalmente o por administradores; otros siete permitieron la ocupación de hecho de las tierras por parte de pobladores indios, chilenos y mestizos, o bien les arrendaron y subarrendaron, utilizándolos como prueba del cumplimiento de los requisitos exigidos por la ley para transformarse en propietarios (poblar e invertir mínimo capital en ganado). Otras tres concesiones fueron más tarde rematadas y adquiridas por ganaderos del territorio, en tanto las trece restantes se transformaron en propiedades vendidas a inversores de origen chileno y a empresarios de capital federal y provincia de Buenos Aires. Véase Bandieri y Blanco, "Política", 2009, pp. 163-199.

${ }^{6}$ Bandieri et al., "Propietarios", 1995, vol. 5, pp. 133-152. 
tenían su mayor inversión en el área pampeana y/o en otros rubros económicos (Züberbhuler, De Bary, Busader Azize y Cía.). Otros pertenecían a familias que ya desarrollaban actividades agroganaderas y comerciales en distintas áreas del país, especialmente bonaerenses, y expandieron sus inversiones avanzando hacia el oeste para aprovechar las posibilidades que las nuevas tierras del sur ofrecían (Lafontaine, Herrera Vegas, Anchorena, son algunos de ellos). Al igual que sucedió en otros lugares del país, y particularmente en la Patagonia, una compañía de origen inglés -The Argentine Southern Land Company Ltd.- estableció en Neuquén uno de sus establecimientos ganaderos, aunque fue en los territorios de Chubut y de Santa Cruz donde concentró mayores superficies. También se conformaron grandes estancias a partir de procesos de acumulación iniciados generalmente en la propia región mediante actividades comerciales y/o ganaderas. Estos últimos hicieron del territorio neuquino el centro de sus negocios y constituyeron un conjunto muy variado con resultados también diferentes en función de la extensión de la tierra obtenida, de la forma y la época en que accedieron a la tierra y de la aptitud ganadera de la misma, así como de la disponibilidad de capital, posibilidad de acceso al crédito y estrategias productivas y comerciales puestas en práctica. Resultan particularmente interesantes, en este conjunto, algunos casos en los que se combinó comercio -almacenes de ramos generales y acopio de frutos del país- con producción ganadera, logrando una importante consolidación del patrimonio territorial (Zingoni, Rambeaud). Finalmente, fue posible observar la compra de considerables superficies a adjudicatarios originales que especularon con sus tierras vendiéndolas a poco de obtenidas en propiedad, por parte de sociedades anónimas de origen chileno. Ubicadas en las áreas cordilleranas y en el sur de Neuquén, con las mejores aptitudes productivas, estas tierras fueron adquiridas por sociedades conformadas en Chile mayormente entre 1904 y 1906 con el explícito fin de adquirir y/o arrendar campos en la región para su puesta en explotación ganadera tanto en el sur chileno como en el argentino, en un contexto altamente favorable caracterizado en ambos países por procesos de expansión de las fronteras, de entrega de tierras públicas en inmejorables condiciones y de intensificación de relaciones comerciales a través de una cordillera que funcionaría la mayor parte de las próximas dos décadas con un régimen libre de impuestos aduaneros (Chile y Argentina, Gente Grande, Ganadera del Limay, General San Martín, entre otras). ${ }^{7}$

Los trabajos de algunos historiadores -como Mateo Martinic Berós desde Punta Arenas o Elsa Mabel Barbería desde Santa Cruz- advertían de la presencia de esas inversiones en las áreas más australes del país sobre

${ }^{7}$ Blanco, “Estado”, 2001, pp. 165-199, y Míguez, Tierras, 1985, pp. 256-266. 
fines del siglo XIX y principios del XX. ${ }^{8}$ Los estudios de Susana Bandieri para el norte de la Patagonia daban cuenta también de la existencia en Neuquén de una sociedad que los documentos y los pobladores denominaban comúnmente Chile-Argentina. ${ }^{9}$ Era un caso notorio por la extensión de las superficies adquiridas, pero aun así aparecía como excepcional. La documentación analizada para estudiar el proceso de distribución y ocupación de tierras públicas en el territorio de Neuquén y los registros notariales chilenos, permitieron descubrir que había otros casos, incluso para el vecino territorio de Río Negro. ${ }^{10}$ No era entonces una realidad sólo visible en el extremo sur del país o un caso aislado en la norpatagonia. Se presentaba, por lo contrario, lo que parecía ser un patrón de inversión común con presencia en la mayoría de los territorios patagónicos.

Esta práctica o estrategia empresarial guarda relación directa con un funcionamiento regional común, como ya se dijera, entre las provincias de ultracordillera y los espacios andinos incorporados al Estado nacional argentino en el cambio de siglo. Independientes respecto de los centros económicos hegemónicos en ambos países, las áreas andinas se caracterizaron por una intensa y rica convivencia cultural, social, productiva y comercial con las sociedades del sur chileno. La cordillera de los Andes se constituía así en el eje articulador de todo ese espacio. ${ }^{11}$

Este trabajo pretende entonces realizar una aproximación a esa modalidad de constituir sociedades anónimas con fines agroganaderos y comerciales a ambos lados del macizo andino en el sur, así como analizar en particular el origen, itinerario y formas de organización adoptadas por la más importante de esas sociedades en Neuquén: la Comercial y Ganadera Chile y Argentina. En función de ello y del tipo de fuentes a las que se ha tenido acceso, tal aproximación no pretende -ni puede- considerarse un estudio de empresas en el sentido que los debates teóricos y la producción

\footnotetext{
${ }^{8}$ Martinic, Magallanes, 1972, y Barbería, Dueños, 1995.

${ }^{9}$ Bandieri, "Actividades", 1993. También véanse Bandieri y Blanco, "Propietarios", 1998, pp. 43-74, y Blanco, "Tierra”, 2002.

${ }^{10}$ Se trabajó intensivamente en los archivos y bibliotecas provinciales, nacionales y chilenos que se detallan al final del trabajo. Para estos casos se relevaron especialmente los Registros de Conservadores de Santiago de Chile y Valparaíso. El caso mencionado de Río Negro es el de la Sociedad Agrícola y Ganadera del Limay, entre cuyos socios se cuentan muchos nombres que aparecen en las otras sociedades que se tratarán en este trabajo para el caso de Neuquén, como Edwards, Ossa, Subercaseaux, Concha, Ureta, Larrain, Amunátegui, Riesco, Errázuriz, Tornero, entre otros. La sociedad se conformó en Santiago de Chile en 1905 con el objeto de adquirir 60000 ha de terreno situadas en el territorio de Río Negro para la crianza de ganado y el de administrar otras propiedades en la provincia chilena de Llanquihue. Escritura de conformación de la Sociedad Agrícola y Ganadera del Limay, Santiago de Chile, 7 de enero de 1905, en Archivo Histórico de Santiago de Chile (en adelante AHSCH), Registro de Conservadores de Santiago de Chile, notaría de Mariano E. Melo.

${ }^{11}$ Bandieri, “Cordillera”, 1991, pp. 133-165, y “Áreas”, 1996, pp. 175-200.
} 
historiográfica de las últimas décadas han otorgado a esta línea de trabajo, con formas específicas de abordaje. ${ }^{12}$

\section{ORIGEN, ITINERARIO Y PRÁCTICAS DE LAS SOCIEDADES GANADERAS Y COMERCIALES CHILENAS}

A fines del siglo XIX, como ya se señaló, tanto Chile como Argentina expandían sus fronteras y distribuían las tierras incorporadas para su ocupación y puesta en producción. Mientras el primero necesitaba proveerse de productos ganaderos, la Patagonia argentina -sobre todo las áreas cordilleranas- presentaban las condiciones necesarias para responder a esa demanda. Existían asimismo los capitales -de origen diverso- dispuestos a invertir en la puesta en producción de las tierras. Desde conocidos financistas y "rentistas"-así se declaraban- hasta importantes ganaderos, agricultores, mineros, industriales, comerciantes y profesionales radicados en Chile, suscribieron acciones de las sociedades anónimas que a principios del siglo XX se fueron conformando en ese país. Casi siempre el punto de partida eran propiedades ya adquiridas o en vías de serlo a ambos lados de la cordillera, que se incorporaban como parte del capital social. El objetivo central era la puesta en producción ganadera de las mismas y la comercialización en los mercados chilenos, así como la transformación y exportación de los productos obtenidos. La cercanía de las áreas cordilleranas patagónicas respecto de las ciudades y puertos del Pacífico y las enormes distancias con los mercados atlánticos, que se acrecentaban por una comunicación aún inexistente, hacían atractiva y segura la iniciativa de expandirse a través de los Andes hacia estas regiones.

En casi todos los casos detectados se ha podido conocer que se trató de empresarios instalados en las provincias del sur chileno que, luego de desarrollar una trayectoria económica y social en esas regiones que les permitió cierta acumulación de capital y la constitución de redes sociales, solicitaron tierras para colonizar al Estado chileno y terminaron conformando para ese fin sociedades anónimas. ${ }^{13}$ Para ello, se asociaron con influyentes actores sociales y económicos de Santiago de Chile como Riesco, Subercaseaux, Ossa, Brown, Döll, Larraín, Bulnes, Maturana, Kuffré, Urzúa, etc. Uno o más de estos apellidos se repetirán en todas y cada una de las cinco

${ }^{12}$ Barbero, "Historia", 2006, pp. 153-154.

${ }^{13}$ Entre las sociedades detectadas en los archivos chilenos, además de las que tuvieron directa relación con el espacio neuquino, puede mencionarse a Colonizadora Bodudahue, Explotadora de Llanquihue, Rupanco, Yelcho Palena, Industrial de Aysén, Río Baker o Explotadora del Valle Simpson. Bengoa, Haciendas, 1990, t. II, y Borgoño, Colonización, 1913, en AHSCH Biblioteca, y Registros de Conservadores de Santiago de Chile y de Valparaíso. 
sociedades anónimas que entre sus activos incluyeron tierras adquiridas en Neuquén al comenzar el siglo XX, según se desprende de las respectivas escrituras de constitución. En lo que parece una réplica de lo sucedido con muchas concesiones similares en Argentina, estas sociedades recibieron considerables extensiones de tierra para colonizar en las provincias del sur chileno, instalaron unos pocos inmigrantes -algunos de los cuales ni siquiera lo eran- y obtuvieron de ese modo la propiedad de parte de las superficies. Luego, o en simultáneo, cruzaron los Andes para invertir en tierras ubicadas al este de ese cordón cordillerano.

Así originadas, las sociedades que perduraron al menos hasta iniciada la segunda década del siglo XX o algunos de sus socios en los casos en que se produjo la disolución societaria optaron, antes o después de que la cordillera se transformase en un límite real y no sólo legal entre ambos países ${ }^{14}$ por concentrar sus intereses en Argentina. La nueva situación de las décadas de 1930 y 1940 las llevaría a readaptarse y buscar los medios para responder a las demandas de un mercado atlántico con otras necesidades y requerimientos. Expresión de ello sería la activa participación en la sociedad regional de sus propietarios o sus representantes y administradores, así como la expansión de las inversiones en la adquisición y/o arriendo de campos de invernada en la provincia de Buenos Aires.

A partir del análisis de fuentes catastrales y registros notariales ${ }^{15}$ fue posible hasta el momento contabilizar para Neuquén al menos cinco casos en los que las referidas sociedades anónimas se constituyeron con idénticos fines: compra de tierra a ambos lados de la cordillera andina, explo-

\footnotetext{
${ }^{14}$ La necesidad de los gobiernos chileno y argentino de generar alternativas a los modelos económicos esencialmente agroexportadoras de ambos países, iniciando la consolidación de un mercado interno aún en ciernes generó una serie de medidas que pretendían poner fin al libre tránsito comercial a través de los múltiples pasos cordilleranos en el sur de los Andes. Fue sobre todo a fines de la década de 1920 cuando el gobierno chileno impuso barreras aduaneras al comercio a través de la cordillera andina, fijando altos impuestos a la introducción de ganado procedente de Argentina -incluidos los pasos de Lonquimay y Pucón, en territorio neuquino. Esta medida tuvo importantes efectos regionales a los que se sumarían los derivados de la crisis internacional de 1929-1930 y de las mayores barreras aduaneras que los gobiernos argentino y chileno dispusieron en la década de 1940 para el comercio bilateral. Esto último, en coincidencia con una clara política orientada a consolidar la situación territorial y el mercado interno en ambos países en un contexto de desarrollo industrial sustitutivo, lo que terminaría por desarticular el histórico funcionamiento económico regional asociado al régimen de "cordillera libre". Bandieri, "Estado", 2001, pp. 345-374.

${ }_{15}$ Entre las fuentes utilizadas se encuentran los duplicados de mensura y la nomenclatura catastral de las propiedades, en Dirección Provincial de Catastro de Neuquén (en adelante DPCN); Registros de Conservadores de Santiago de Chile y de Valparaíso entre los años 1905 y 1911, en AHSCH; Memorias de la Oficina de Mensuras de Tierras al Ministro de Colonización de Chile entre 1905 y 1910, en AHSCH, y guías comerciales y publicaciones periódicas que se citan en el trabajo.
} 
tación agroganadera de las mismas, comercialización de esa producción y sus derivados, entre los más importantes.

El primero de ellos es el de la Sociedad Francesa, Agrícola y Minera de Valparaíso, que adquirió 15000 hectáreas a otra sociedad chilena en 1910 y conformó la estancia Cerro Los Pinos en los departamentos cordilleranos de Huilliches y Lácar. ${ }^{16}$ Esta sociedad, en la que participaba Esteban María de Larminat y a la que además representaba, explotaría la propiedad a través del mismo hasta su disolución en una fecha cercana a 1920.

El segundo caso es el de la Sociedad Comercial y Ganadera del Lanín. Uno de sus socios, Constantino Enchelmayer, radicado en el área de Valdivia, había arrendado a fines del siglo XIX y comprado en los primeros años del siguiente 25000 hectáreas en el área andina de Neuquén, estableciendo allí una importante estancia -Mamuil Malal. ${ }^{17}$ El Estado chileno le había concedido en 1904, asimismo, una superficie de 243000 ha para colonizar en el valle de Trancura y en la zona norte del lago Villarrica en la provincia de Valdivia, las que de no existir la cordillera de los Andes se habrían unido a las tierras obtenidas en Neuquén. En 1905, al conformarse la sociedad anónima, las propiedades y la concesión para colonizar fueron incorporadas a la misma, obteniéndose en 1909 la propiedad sobre 15000 hectáreas. ${ }^{18}$

El tercer caso es el de la Sociedad Comercial y Ganadera General San Martín, integrada por comerciantes y corredores de comercio de Valparaíso entre los que se encontraban varios miembros de la familia Camino. $\mathrm{Al}$ igual que Enchelmayer, los hermanos Camino, radicados en el área de Valdivia donde desarrollaban actividades vinculadas a la importación de mercaderías y exportación de frutos del país, ${ }^{19}$ se expandieron hacia otras zonas de Chile y el sur argentino asociándose con otros capitales. Adquirieron fundos para crianza en el área de Valdivia -Remehue y Trafun- con un total de 37500 hectáreas e instalaron empresas de navegación de ríos y

${ }^{16}$ Lotes 21, 24, 25 y 28 de la sección XXXIII, con 3750 ha cada uno (nomenclatura catastral 15-RR-5339, en DPCN).

${ }^{17}$ Duplicado de mensura 372, en DPCN.

${ }^{18}$ Decreto núm. 928 del 29 de abril de 1904. El título definitivo sobre las 15000 hectáreas fue concedido por el gobierno chileno a la Sociedad Ganadera del Lanín en 1912, por decreto núm. 62. República, Quinta, 1912, pp. 9-10 y 40-44, en AHSCH. Los estatutos de la sociedad fueron aprobados por escritura pública el 5 de enero de 1905 y modificados el 1 de marzo de ese año. AHSCH, Registro de Conservadores de Santiago de Chile, notario Marcelino Larrazábal Wilson, 1905, fs. 41-48 y 655-656.

${ }^{19}$ Estas actividades se veían beneficiadas a fines del siglo XIX por el desarrollo industrial europeo y el corrimiento de la frontera en Chile, que habían generado ventajas arancelarias al tiempo que ampliado los mercados, permitiéndole a muchas de estas casas comerciales constituirse en proveedoras de los ejércitos y las nuevas colonizaciones de la Araucanía. Espejo, Guía, 1908, pp. 130, 131, 152, y Empresa, Guía, 1913, pp. 435-436, 996, 1157. 
lagos en ambos lados de la cordillera. Obtuvieron asimismo la concesión para la construcción de un ferrocarril chileno que uniría Collilelfu con San Martín de los Andes en Neuquén, aprovechando la navegación de los lagos cordilleranos y en septiembre de 1905 integraron la nueva Sociedad Comercial y Ganadera General San Martín, incorporando sus activos. ${ }^{20}$ Ese mismo año lograron que se les transfiriera una concesión para colonizar 37300 hectáreas en los lagos Panguipulli, Perihuaico y Reñihue, colonización que según la inspección realizada en 1907 aún no había sucedido, habiendo en cambio aprovechado esa situación para adquirir tierras a indígenas y particulares. ${ }^{21}$ En los años siguientes obtuvieron superficies en el área andina de Neuquén por compra -49 300 hectáreas- y en arrendamiento -20 000 hectáreas-, sobre las que comenzaron a desarrollarse explotaciones ganaderas. ${ }^{22}$

El cuarto y el quinto de los casos detectados son los de la Sociedad Comercial y Ganadera Chile y Argentina y la Sociedad Ganadera Gente Grande, los que se tratarán particularmente en el siguiente apartado. Como ya se dijera, a estas sociedades que han podido hasta ahora ser identificadas para el caso neuquino, se suman otras con presencia en los territorios patagónicos de Río Negro, Santa Cruz y Tierra del Fuego. Sobre todo en estos últimos, donde la ocupación y puesta en producción se inició desde el área de Punta Arenas hacia el extremo austral argentino, y donde la práctica de conformar sociedades anónimas fue muy importante según se desprende del minucioso análisis de Barbería. ${ }^{23}$

Al parecer, la Sociedad Anónima se constituyó en los primeros años, apenas iniciado el siglo XX, en una modalidad privilegiada por los actores sociales para organizar la actividad empresarial, limitando responsabilidades y diversificando riesgos. Estas sociedades se habrían conformado a partir de la existencia de redes económicas previas, dando lugar a nuevas alianzas estratégicas. Nos referimos a la confluencia en estas formas societarias de actores sociales instalados en las áreas de Valdivia, Puerto Mont, Osorno, que habían logrado acumular cierto capital en actividades comerciales y productivas y en algunos casos habían obtenido tierras en las zonas

${ }^{20}$ Escritura de Constitución Sociedad Anónima General San Martín Compañía Comercial y Ganadera, en AHSCH, Registro de Conservadores de Valparaíso, notario José María Vega, 1905, fs. 663-674. Modificación de Estatutos, en AHSCH, Registro de Conservadores de Valparaíso, Notario José María Vega, 1907, fs. 288-293.

${ }^{21}$ Ministerio, Memoria, 1908, p. 75.

${ }^{22}$ Las superficies adquiridas por compra en 1907 correspondían a uno de los socios, Demetrio Aguerre, quien poseía esa superficie desde 1905 en que la había adquirido a Carlos Cernadas, concesionario original de la Ley de Colonización núm. 817 en Neuquén. Las superficies arrendadas lo fueron en 1909 al Estado nacional argentino en la misma área, adquiriendo luego la mitad en propiedad.

${ }^{23}$ Barbería, Dueños, 1995. 
de nueva colonización a ambos lados del macizo andino, con otros actores vinculados al ámbito de las finanzas, el comercio y la producción agrícola y minera, radicados en el centro económico y político chileno: Santiago y Valparaíso. Los primeros encontraban así la posibilidad de expandirse, en tanto los segundos encontraban nuevas áreas para invertir sus capitales y obtener rentabilidad en las mejores condiciones.

Resulta indispensable tener presente que en esos años se daba una serie de condiciones que constituía un abanico de posibilidades para la inversión de capital y el desarrollo de las actividades productivas y comerciales en espacios nuevos, como eran la Araucanía chilena y la Patagonia argentina, recientemente incorporadas a los respectivos estados nacionales. En el sur chileno las actividades de importación y exportación, así como las industrias ligadas a los subproductos ganaderos transitaban uno de sus mejores momentos; la mayor parte de las tierras aptas de ese país estaban destinadas a la producción de cereales, lo que hacía necesario importar ganado para alimentar a la población y proporcionar materia prima a curtiembres, textiles, graserías, etc. El sur argentino, en cambio, reconocía una vinculación económica y comercial ancestral con las ciudades y puertos chilenos antes que con el centro económico del área pampeana, orientado hacia el Atlántico con una producción de alta calidad, a miles de kilómetros de distancia y sin comunicaciones aun suficientemente desarrolladas. Las posibilidades de desarrollo ganadero y las facilidades para trasponer los Andes en pocos días a través de los numerosos pasos existentes en su tramo patagónico, generaban las condiciones para el desarrollo de una complementariedad económica y comercial con las provincias sureñas del vecino país. A esta situación, se sumaba la disponibilidad de tierras en poder de los Estados nacionales de Chile y de Argentina, que en esos años eran entregadas con liberalidad, mínimas exigencias y excelentes condiciones de precio; así como extensas superficies apropiadas por particulares que ninguna intención mostraban de ponerlas en producción y eran ofrecidas en venta a muy bajo precio.

\section{El estudio de caso: la Sociedad Anónima Chile-Argentina, COMPAÑía COMERCIAL y GaNADERA Y LA SOCIEDAD GANADERA GENTE GRANDE}

Con propiedades en ambos lados de la cordillera, esta sociedad es el ejemplo más importante de la estrategia de inversión que venimos describiendo. Llegó a concentrar por compra a sus concesionarios originales una superficie de 419737 hectáreas en propiedad en el sur del área andina de Neuquén, constituyendo una serie de estancias que fueron manejadas em- 
presarialmente como una única unidad de producción. Se trata, sin duda, de la mayor superficie concentrada por un propietario en todo el territorio, independientemente del origen del capital invertido o la nacionalidad. Baste sólo decir que en sus manos se encontraba 11.7\% de toda la tierra privatizada en el territorio neuquino. ${ }^{24}$

La Sociedad Anónima Chile-Argentina, Compañía Comercial y Ganadera -en adelante Chile-Argentina-, se constituyó formalmente en septiembre de 1904 en Valparaíso, contando como accionista mayoritario a Federico Hube -10 000 acciones- y un número importante de otros socios entre los que figuraban miembros de las familias Subercaseaux, Kuffré, Döll, Maturana, Ochinger, Ramírez, Urzúa, Lira, Prieto, Errázuriz, entre otros. El objetivo de la sociedad era adquirir el activo y pasivo de la firma Hube y Achelis con sede en Puerto Montt, incluidos los terrenos y la explotación de negocios comerciales y productivos que la misma poseía en Chile y Argentina, la compra de ganado y sus productos, la apertura de sucursales y la adquisición y explotación de embarcaciones para el transporte de ganado y mercaderías. La administración estaría en manos de un directorio, que designaría un director gerente en Puerto Montt para hacerse cargo de los intereses de la sociedad en ese lugar. El primer director gerente fue Federico Hube. ${ }^{25}$

La sociedad Hube y Achelis, que propició e integró la nueva sociedad, abarcaba los rubros de inversión más variados incluido el turismo en la zona andina norpatagónica -sur de Neuquén y el área de San Carlos de Bariloche en Río Negro-, a la que presentaba en sus propagandas como la Suiza Chilena y Argentina. Federico Hube -cónsul argentino acreditado en Puerto Montt- y Adolfo Achelis pertenecían a una importante firma comercial exportadora de esa ciudad portuaria del sur chileno cuando instalaron el centro de sus operaciones comerciales e industriales en Argentina, más precisamente en la ciudad de Bariloche. Uniendo Puerto Montt y Bariloche, la compañía brindaba un servicio de transporte por

${ }^{24}$ Para 1920 se había prácticamente completado en Neuquén el proceso de privatización de tierras si se lo compara con las superficies privadas y fiscales existentes al finalizar el siglo XX. Se habían entregado en propiedad un total de 3570820 hectáreas distribuidas entre 306 beneficiarios. Blanco, "Tierra", 2002, cap. IV, p. 173.

${ }^{25}$ La creación de la sociedad fue aprobada por decreto superior núm. 3487 del 24 de octubre de 1904 y declarada legalmente fundada por decreto núm. 4206 del 24 de diciembre de ese mismo año. Escritura de constitución de la Sociedad Comercial y Ganadera Chile-Argentina, en AHSCH, Registro de Conservadores de Valparaíso, notaría de José María Vega, 1905, acta 208, fs. 259-276. En 1906 la sociedad modificó sus estatutos. Además de los socios antes mencionados, el Banco Español aparecía como uno de los más importantes con 10000 acciones. Modificación de Estatutos de la Sociedad Comercial y Ganadera Chile-Argentina, en AHSCH, Registro de Conservadores de Valparaíso, notaría de José María Vega, año 1906, acta núm. 98, fs. 144-148. En cuanto a los apellidos de los socios, ya se ha hecho referencia con anterioridad a muchos de ellos, todos miembros selectos de la elite política y económica de Chile. 
tierra y agua con sucesivas paradas en sus numerosas casas comerciales y hoteles en territorio chileno, en un viaje que duraba 20 horas. Un sistema de vapores servía para cruzar los lagos, incluido el Nahuel Huapi, donde la compañía manejaba también el transporte de lanas y cueros que salían por Puerto Montt, desde donde se regresaba con mercaderías varias para el consumo de la región. ${ }^{26}$ Mediante subvención anual del gobierno argentino, la sociedad estuvo a cargo del servicio de correo, tendiendo sus propias líneas telefónicas con esa ciudad. Tres casas comerciales en Chile, una casa central en San Carlos de Bariloche y otras en territorio neuquino, bodegas, muelles, vapores, lanchas y embarcaciones menores, coches, carros y carretas de tracción a sangre para el servicio trasandino, $170 \mathrm{~km}$ de líneas telefónicas, 2000 ha en Chile por donde pasaba el camino, una muy importante cantidad de tierras en propiedad y en arrendamiento en Neuquén, otros campos en Río Negro, un molino harinero en Bariloche, lavadero de lana, aserradero, planes de colonización, 998 clientes declarados en Chile y 400 en Argentina, hablan de la importancia de esta compañía que consiguió del gobierno nacional argentino en 1904 que la zona que abarcaba sus actividades económicas quedara excluida de la jurisdicción aduanera argentina. ${ }^{27}$

Apenas conformada, la sociedad obtuvo, al igual que en otros casos antes mencionados, la cesión de derechos y obligaciones del contrato de colonización que Horacio Rodríguez Bravo había realizado con el Estado chileno en el área de Vega Hermosa y Cancha Rayada. Siguiendo el mismo patrón descrito, nunca llegaron a desarrollar un proceso colonizador. ${ }^{28}$

En cuanto a la adquisición de tierras en Neuquén, cuatro importantes concesiones para colonizar, concedidas y luego donadas por el Estado argentino a Juan Repetto, Francisco Uriburu, Dolores Uriburu de Uriburu y Elisa Uriburu de Castells-Luis Castells (hijo), colindantes entre sí y ubicadas en el sur del área andina y en el sudeste del territorio, fueron adquiridas en bloque en 1904 por Hube y Achelis sumando un total de 260623 ha que fueron transferidas a la Chile-Argentina en el momento de su constitución. ${ }^{29}$ Otras dos concesiones para colonizar, adquiridas al gobierno nacional argentino hacia fines de siglo XIX por Pedro Gartland y Encarnación Dirube de Gartland, fueron vendidas en 1899 a la Sociedad

${ }^{26}$ La Nación, 29 de junio de 1901.

${ }^{27}$ Decreto del 23 de agosto de 1904, firmado por el presidente Roca, "Chile y Arjentina. De puerto Montt al gran lago argentino Nahuelhuapi" [sic]. Obsequio de la Sociedad Comercial y Ganadera Chile-Argentina a sus accionistas, Valparaíso, 1904, en Archivo Histórico Regional Cooperativa de Electricidad, San Carlos de Bariloche (en adelante AHR), Cooperativa de Electricidad, San Carlos de Bariloche.

${ }^{28}$ Memoria de la Inspección General de Colonización e Inmigración, Santiago de Chile, 1910, p. 35, en AHSCH, Colonización.

${ }^{29}$ Duplicados de mensura $8,11,13$ y 28 , en DPCN. 
Anónima Crédito Italiano quien escrituró en $1902 .{ }^{30}$ Tres años después, esta sociedad vendió la superficie a José G. Ramila y Juan Enrique Concha Subercaseaux, miembros de importantes familias chilenas vinculadas a la banca y a otras actividades mineras y agrícolas en su país. ${ }^{31}$ Sólo 17 días después de realizada la operación, los compradores vendieron las tierras en Santiago de Chile a la Sociedad Agrícola del Neuquén, integrada por los mismos Ramila y Concha Subercaseaux, además de Enrique Nieto, Manuel González y José Ureta. Esta sociedad, constituida al sólo efecto de adquirir y explotar los referidos campos, se comprometía en el mismo acto a fusionarse legalmente con la Chile-Argentina a cambio de acciones de la misma. ${ }^{32}$ De tal manera, esta última llegó a reunir para 1905 , como ya se anticipara, un total de 419737 ha en propiedad en Neuquén (véase diagrama 1), en tierras de la mejor calidad productiva, aquellas que por sus características geográficas permitían concentrar en grandes unidades de producción campos de invernada y veranada, y favorecían un desarrollo redituable de la actividad ganadera predominante. ${ }^{33}$ Ese mismo año la sociedad estableció en Argentina una sucursal administrada por un directorio local. $^{34}$

${ }^{30}$ Duplicados de mensura 4, 20, en DPCN.

${ }^{31}$ El origen y evolución de estas familias y sus intereses económicos, pueden verse en Villalobos, Origen, 1988, pp. 146-160. El caso de los Subercaseaux, hijos de inmigrantes franceses, es un claro ejemplo de la trayectoria seguida por familias tradicionales chilenas, emparentadas entre sí, cuyos capitales iniciales se hicieron en la minería y el comercio y luego se diversificaron en importantes haciendas y otras actividades agroindustriales como la vitivinicultura. Bauer, Sociedad, 1994, pp. 56, 207-208.

${ }_{32}^{32}$ La Sociedad Agrícola del Neuquén se constituyó en Santiago de Chile en abril de 1905, con el objeto mencionado y un capital de 125000 libras esterlinas. Escritura de constitución de la Sociedad Agrícola del Neuquén, en AHSCH, Registro de Conservadores de Santiago de Chile, notaría de Marcelino Larrazábal Wilson, 1905, acta 340, fs. 271-278. La sociedad se fusionó con la Sociedad Comercial y Ganadera Chile-Argentina en Valparaíso en junio de 1905, y de acuerdo con el convenio del 24 de abril de ese año entregó los terrenos que habían quedado hipotecados por el saldo del precio. El mismo había sido de 100000 libras esterlinas, pagaderas de la siguiente forma: $50 \%$ en doce meses, $25 \%$ en 18 meses y el restante $25 \%$ en 25 meses con un interés de $6 \%$ anual. Más allá de la hipoteca constituida en primer grado con el Banco Crédito Italiano, se estableció una segunda hipoteca a favor de la sociedad Chile-Argentina como garantía. Esto incrementaba, por fusión, el capital de esta última a 400000 libras esterlinas, divididas en 80000 acciones de cinco libras cada una. Escritura de fusión de sociedades, en AHSCH, Registro de Conservadores de Valparaíso, notaría de José María Vega, 1905, acta 208, fs. 496-510.

${ }^{33}$ La notable fertilidad de estas tierras se describe con detalles en la documentación de las mensuras. Por otra parte, la trayectoria empresarial de la sociedad Chile-Argentina ya ha sido dada a conocer parcialmente en Bandieri y Blanco, "Propietarios", 1998.

${ }^{34}$ El directorio estaba integrado por David Tezanos Pinto, Francisco S. Uriburu, Miguel García Fernández y Alberto Rodríguez Larreta, en tanto el director gerente era Alejandro von Heyking. La sucursal fue autorizada por el poder ejecutivo nacional el 21 de junio de 1905. Monitores de Sociedades Anónimas y Patentes de Invención, 1900-1948, Buenos Aires, en Banco Central de la República Argentina, Buenos Aires (en adelante BCRA), Biblioteca Tornquist, t. II, 1904-1906, núm. 14, diciembre de 1906, pp. 316-318. 


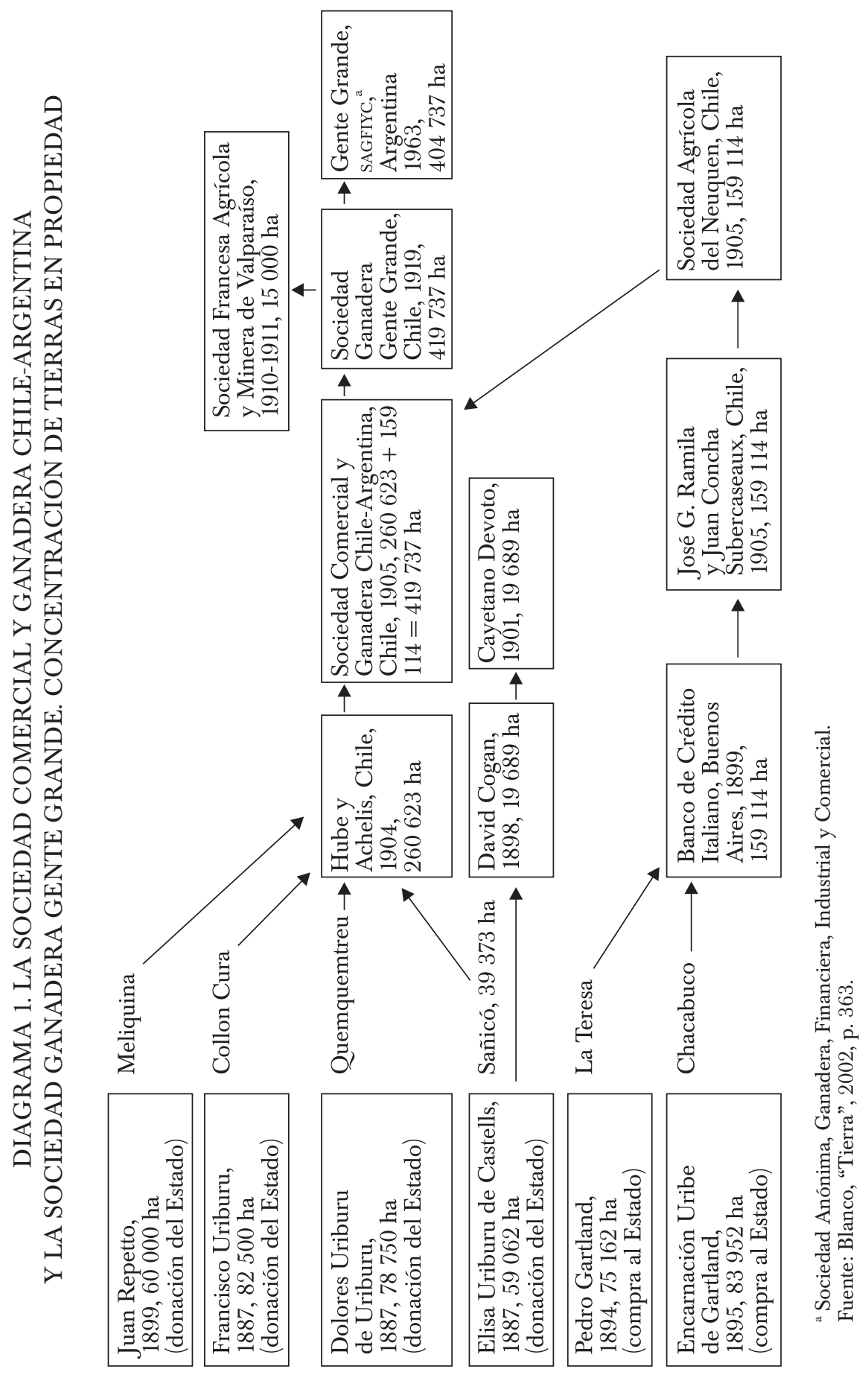


En las superficies adquiridas en territorio neuquino se conformaron seis estancias de reconocida importancia productiva, denominadas Meliquina, Chacabuco, Quemquemtreu, Collon Cura, Sañicó y La Teresa, ubicadas en los departamentos Huilliches, Lacar, Los Lagos y Collon Cura, colindantes entre sí. Años más tarde, en 1910 y 1911, la sociedad ChileArgentina vendió a otra firma chilena una fracción de 15000 ha de sus campos sobre la que se constituyó posteriormente la estancia Cerro Los Pinos de la familia Larminat. Después de esta venta, la superficie total en manos de la sociedad alcanzaba las 404737 ha en el territorio. ${ }^{35}$

En cuanto a la explotación de los campos neuquinos, la misma era dirigida desde Chile por el directorio, con representación comercial en Buenos Aires -firma Waldron \& Wood-, y se administraba desde la estancia Quemquemtreu en Neuquén. Todos estos establecimientos ganaderos se destacaron desde el comienzo por el nivel de calidad de sus ganados ovinos y vacunos, trasladándose estos últimos a través de la cordillera de los Andes para comercializarse en los mercados chilenos. La producción se organizaba también mediante puesteros a los que la sociedad comercializaba la producción, efectuándole adelantos en efectivo a través de vales y descontándoles los gastos derivados del cuidado y posterior transporte de los animales. ${ }^{36}$ Estos servicios también eran brindados a otros pequeños productores del área, sin relación de dependencia productiva aunque sí comercial.

En 1916, la Sociedad Comercial y Ganadera Chile-Argentina vendió a Primo Capraro y Cía. su sección comercial e industrial en San Carlos de Bariloche -aserradero, molino y corralón de maderas-, y tres años después entró en proceso de liquidación. La asamblea extraordinaria de accionistas reunida en diciembre de 1918 aprobó la disolución anticipada, luego de tres balances negativos -1915-1917, en el contexto de la primera guerra mundial-, y estableció un compromiso de venta del activo y el pasivo a la Sociedad Ganadera Gente Grande. ${ }^{37}$

${ }^{35}$ Podemos asegurar que estas fueron las superficies adquiridas en el territorio en virtud del trabajo realizado con la documentación referente a la apropiación de tierras en Neuquén. Sin embargo, hemos detectado un dato que podría estar indicando la posesión de tierras en el vecino territorio de Río Negro. En 1914, con motivo de un juicio entre la sociedad y su administrador, Federico Olshausen, este declaraba que entre 1904 y 1910 se había hecho cargo de la administración de la estancia San Ramón, en ese territorio. Archivo de la Justicia Letrada del Territorio de Neuquén (en adelante AJLTN), exp. 853, f. 42, 1914.

${ }_{36}^{36}$ AJLTN, exp. 490, f. 634, 1912.

${ }^{37}$ De los socios presentes en la asamblea que decidió la disolución el 27 de diciembre de 1918, cuyo número se había ampliado notablemente, se destacan por el número de acciones que poseían el Banco Germánico, Duncan Fox y Cía., el Banco Popular, Ricardo Lara, el Banco de Chile, Sara Braun, el Banco de Punta Arenas y Alejandro Valdés Riesco. Escritura de disolución de la sociedad, en AHSCH, Registro de Conservadores de Santiago de Chile, notaría de Javier Vergara Rodríguez, 1919, acta 108, fs. 115-118, y acta 219, fs. 231-232. 
La firma que adquiría los bienes de la empresa Chile-Argentina era una de las cuatro sociedades ganaderas más importantes del área magallánica, con sede central en Santiago de Chile. Se había constituido en marzo de 1905 sobre la base de la sociedad Wehrhahn Hobbs y Cía. -que integraban César, Hernán y Augusto Wehrhahn, Rodolfo Stubenrauch y Ernesto Hobbs-, a la que había adquirido los bienes en el sur de Chile. ${ }^{38}$ Se constituía así la Sociedad Ganadera Gente Grande, con fines muy parecidos a los observados en las otras sociedades anónimas analizadas. El capital social ascendía a 1600000 pesos, con un consejo directivo y un administrador con residencia en Magallanes. ${ }^{39}$ En 1919, con motivo de adquirir los bienes de la compañía Chile-Argentina, se reformaron los estatutos, se fijó domicilio en Santiago y se designaron administradores en las sucursales o establecimientos. ${ }^{40}$ La Sociedad Ganadera Gente Grande poseía asimismo en Chile, en plena frontera y casi lindante con la colonia Maipú en el límite entre los departamentos cordilleranos Huilliches y Lacar de Neuquén, el establecimiento Pirehueico donde existía un importante aserradero desde el cual proveían a varios pobladores del territorio neuquino.

${ }^{38}$ Acta de promesa de venta, en AHSCH, Registro de Conservadores de Santiago de Chile, notaría de Manuel Almaza, acta 934, fs. 631-635. Rodolfo Stubenrauch había nacido en Alemania y luego se trasladó a Londres desde donde la firma comercial Alberto Schröeder y Cía. lo envió en 1880 a Valparaíso con un alto puesto y en 1882 lo trasladó a Punta Arenas a cargo de la sucursal. Allí fue apoderado y representante de la firma Wehrhahn y Cía., que más tarde adquirió cambiando el nombre por el de Stubenrauch y Cía. Luego se asoció con Herman Koch. En unión con Wehrhahn y Hobbs fundaron una sociedad ganadera precursora de la Sociedad Ganadera Gente Grande. Al mismo tiempo, el gobierno inglés lo hizo su representante en Punta Arenas y en 1884 lo nombró cónsul de ese país en la ciudad austral. Fue además cofundador del Banco de Punta Arenas y del Frigorífico de Puerto Lara. Wehrhahn Hobbs y Cía., constituida en 1885, era dueña de 120000 ha en la costa de Tierra del Fuego. Chamorro, Bajo, 1936, vol. 1. La firma poseía numerosos terrenos en propiedad y en arrendamiento al fisco chileno en la zona austral de ese país, sobre los cuales habían constituido las estancias Bahía Lee -6 000 ha y 7000 lanares y vacunos-, Gente Grande -80 000 ha, con 65000 animales lanares y vacunos, galpón de esquila, baño, etc.- y El Porvenir -20 000 ha, con 12500 animales, galpones, bodegas, caballerizas, etcétera.

${ }^{39}$ En 1912 la sociedad Gente Grande adquirió los derechos de la isla Dawson en 38311 libras esterlinas. Contaba con una muy importante existencia de ovinos, caballos y vacunos, así como un aserradero de primera clase en la mencionada isla, cuyo gerente era Ernesto Hobbs. También instaló un astillero para construcción y refacción de barcas. Anuario, 1920, pp. 749 y ss., en AHSCH, Biblioteca. La sociedad fue inscrita como sociedad extranjera en el Registro Público de Comercio de Argentina el 22 de mayo de 1921. Monitores de Sociedades Anónimas y Patentes de Invención, Buenos Aires, en BCRA, Biblioteca Tornquist, t. XXXI, año 1922, pp. 195-206.

${ }^{40}$ Escritura de Conformación de la Sociedad Comercial y Ganadera Gente Grande, en AHSCH, Registro de Conservadores de Santiago de Chile, notaría de Manuel Almaza, 1905, acta 987, fs. 661-670. Entre los socios de la nueva compañía figuraban Mariano Edwards, Herman Eberhardt, Ernesto W. Hobbs, Gregorio Lira, Carolina Larraín, José Menéndez, Enrique Nieto, Francisco Ossa, Carlos Rogers, Juan Stuven, Winfield Stern, Rodolfo Stubenrauch, Víctor Tornero, Darío Urzúa, el Banco de Punta Arenas, el Banco Edwards, Manuel Balmaceda, Duncan Fox y Cía., la Sociedad Custodia de Valores, Ernesto Manns, Otto y César Wehrhahn, etc. La reforma de los estatutos en 1919 se encuentra en AHSCH, Registro de Conservadores de Santiago de Chile, notaría de Abraham del Río, 1919, acta 68, fs. 81-87. 
Luego de adquiridos los campos de Neuquén por Gente Grande la explotación de los mismos continuaría siendo dirigida desde Chile, la representación comercial seguiría en manos de la firma Waldron \& Word en Buenos Aires, y el gerente local, en calidad de administrador general, continuaría operando desde el establecimiento Quemquemtreu. Este cargo fue ocupado por Andrés Douglas Reid, administrador y más tarde propietario de una estancia en el territorio, siendo asimismo varias veces presidente de la Sociedad Rural de Neuquén. Del grupo de explotaciones que constituían la sociedad, se vendió luego Sañicó y se agregó Santa Isabel, por desprendimiento de La Teresa.

Todas las estancias surgidas en Neuquén de la sociedad Chile-Argentina y explotadas luego por Gente Grande, se destacaron desde las primeras décadas del siglo por el nivel de calidad de sus ganados ovinos y vacunos. Durante esos años, los animales se trasladaban en pie a través de la cordillera para su comercialización en los mercados trasandinos. Más tarde, una fuente de 1929 daba cuenta de un doble circuito comercial, por el cual esta sociedad enviaba su producción de capones a los frigoríficos de Buenos Aires y Bahía Blanca utilizando la estación Zapala del Ferrocarril Sud ubicada en Neuquén, a $225 \mathrm{~km}$ del establecimiento central, en tanto que los novillos eran trasladados a Chile por el paso cordillerano de Tromen en dirección a los mercados de Temuco, distante $150 \mathrm{~km}$ del mismo. ${ }^{41}$

Las explotaciones estaban dotadas de importante tecnología y organizadas como verdaderas empresas capitalistas en las que se empleaba un número considerable de mano de obra asalariada, características estas de las que daban cuenta diferentes fuentes de la época. Para mediados de la década de 1920, prácticamente la totalidad de los campos se hallaban alambrados, las estancias se comunicaban entre sí por medio de teléfono y poseían balsas propias para el cruce de los ríos. ${ }^{42}$ Contaban asimismo con usina y aserradero propio, bañaderos con una capacidad diaria de 80000 ovejas y amplísimos galpones para esquilar, guardar maquinarias, almacenar la propia producción de cereales, etc. En Quemquemtreu se encontraba la proveeduría para todo el personal. ${ }^{43}$

${ }^{41}$ Biaus y Maldonado, Álbum, 1929, p. 435. Las características de las explotaciones de esta sociedad en Neuquén, han sido parcialmente desarrolladas en Bandieri y Blanco, "Propietarios", 1998.

${ }^{42}$ Para 1940, del capital empleado en ese sentido hablan con elocuencia los metros lineales de alambrados incorporados por la sociedad, que a comienzos de la década de 1940 alcanzaba 1250000 metros. Había contribuido asimismo a la realización de muchas obras, donando madera para la construcción del puente sobre el río Caleufu, construyendo un puente carretero sobre los ríos Quemquemtreu y Chilchuma y uno de cables sobre el río Caleufu para el paso de ganado y jinetes en Meliquina. La Cordillera, año XI, núm. 522, 8 de marzo de 1941, pp. 3-4.

${ }^{43}$ Las características tecnológicas de las explotaciones han sido tomadas de textos y propagandas comerciales de Edelman, Guía, 1924, y Biaus y Maldonado, Álbum, 1929. 
Cabe destacar asimismo la importancia de la cría de ovinos de raza Merino, que anualmente producía alrededor de $550000 \mathrm{~kg}$ de lana de reconocida calidad -de hecho, habían introducido carneros refinados y comprado reproductores de las cabañas más famosas del país en los comienzos-, así como la cría de vacunos que se complementaba con una moderna cabaña de pedigree en la estancia La Vidania de Trenque Lauquen, provincia de Buenos Aires, sitio en el cual poseía además otro establecimiento conocido como Santa Luisa. En ellos se criaban reproductores de raza Hereford, habiendo alcanzado un alto grado de mestización que les permitía entregar sus novillos a los frigoríficos con $80 \%$ de chilled. $^{44}$ También se dedicaron a la cría de caballos puros de carrera y de polo de gran calidad. Para fines de la década de 1920 el conjunto de la explotación era manejado con catorce administrativos y alrededor de 150 peones y capataces. ${ }^{45}$ Sin duda, la sociedad orientó su producción hacia las especies ganaderas más convenientes en función de las posibilidades productivas de sus campos y de los requerimientos del mercado, utilizando eficientemente las posibilidades que estos brindaron en cada momento histórico, a lo largo de una extensa trayectoria en la región, con excelentes condiciones de rentabilidad.

Una significativa continuidad y perduración en el tiempo caracterizaron a la firma, que explotó los campos en Neuquén en forma conjunta hasta 1963 , año en que fueron transferidos a la firma Gente Grande, Sociedad Anónima, Agropecuaria, Industrial, Comercial y Financiera (SAAICyF), con domicilio en la capital federal, representada por el señor Alejandro Menéndez Prendez, quien procedió a enajenar estas tierras entre 1963 y 1973, subdivididas en importantes superficies, a diferentes sociedades de reciente formación como Chacabuco del Neuquén Sociedad Anónima, Agropecuaria y Ganadera (SAAyG); Quemquemtreu S. A. o Santa Isabel S. A. ${ }^{46}$

${ }^{44}$ La Cordillera, año XI, núm. 522, 8 de marzo de 1941, pp. 3-4.

${ }^{45}$ En la década de 1940, las cifras encontradas indican un total de diez empleados de administración y 280 peones permanentes, número que se incrementaba en 400 personas más durante la temporada de esquila. "Gran Bretaña en el desarrollo de la ganadería argentina. La obra de fomento de las sociedades rurales", Buenos Aires Herald, 1944. Véase también La Cordillera, 31 de julio de 1946, p. 6.

${ }^{46}$ Nomenclaturas catastrales 15-RR-23-4459/3649/1139 y 1930, en DPCN. También Escrituras de inscripción de las sociedades, en Registro Público de Comercio de Neuquén (en adelante RPCN), 1970, t. III, vol. II, fs. 981-997, 1975, y t. VIII, fs. 686-693. La decisión de subdividir el patrimonio y conformar distintas sociedades en esos años podría haber estado influenciada por las circunstancias políticas en Argentina, que hacían presumir la apertura de un nuevo ciclo de gobierno peronista y la posibilidad de una reforma agraria similar a la efectuada en Chile por el gobierno socialista de Allende, con la aplicación de la Ley de Reforma Agraria que expropió latifundios con importantes consecuencias sobre la concentración de la propiedad de la tierra. 


\section{CONCLUSIONES}

Como hemos podido observar, la conformación de sociedades anónimas para el desarrollo de actividades comerciales y productivas a ambos lados de la cordillera de los Andes parece haber sido una práctica común en Chile en los primeros años del siglo XX. Este resultó ser un mecanismo ampliamente utilizado por un número considerable de miembros de las elites económicas y políticas del país trasandino para generar procesos de acumulación a partir de la adquisición de tierras, su explotación productiva y la comercialización de los productos obtenidos. La inversión en importantes superficies ubicadas en las áreas andinas patagónicas de Argentina fue un patrón común en ese esquema de funcionamiento.

Al profundizar en la composición social de estas firmas se ha podido observar con claridad la estrategia puesta en marcha por los miembros más tradicionales e importantes de las elites de poder chilenas, con centro en la capital de ese país. En todos los casos, estos sectores orientaron decididamente la inversión de sus capitales en el sentido mencionado, buscando aliarse con aquellas burguesías regionales -sobre todo las del sur chileno- que habían iniciado o en algunos casos consolidado su proceso de acumulación de capital en esas áreas, obteniendo tierras con fines colonizadores por parte del Estado trasandino. Estos grupos regionales de Valdivia, Puerto Montt o Punta Arenas se incorporaron a las sociedades aportando tierras en Chile y en Argentina, en tanto las elites de Santiago y Valparaíso aparecían como los socios que aportaban el capital que permitiría políticas expansivas más amplias. De esa manera, los últimos respondían a su propia estrategia de diversificación de la inversión y del riesgo, al tiempo que aprovechaban el momento justo en que, tanto la Araucanía chilena como la Patagonia argentina se incorporaban a la soberanía de los respectivos Estados nacionales y a la puesta en producción capitalista. Recuérdese además que se trataba de áreas que reconocían una historia previa de funcionamiento económico y social común.

En casi todos los casos analizados, los sectores pertenecientes a las burguesías regionales del sur chileno se retiraron de las sociedades así conformadas antes de finalizar la primera década del siglo XX, recuperaron la posesión de sus campos en territorio neuquino y se dedicaron, algunos antes y otros más tarde, a la explotación personal de sus estancias. En varios casos ampliaron incluso sus campos con la adquisición o arriendo de otras superficies. De esta manera, optaban por una clara inserción regional manteniendo en los primeros tiempos los vínculos con el país vecino en función de las posibilidades del mercado trasandino, relacionándose luego con los mercados atlánticos para lo cual pusieron generalmente en práctica la estrategia de adquirir o arrendar superficies en el área pampeana con 
el objetivo de complementar la cría y el engorde de los animales antes de su comercialización. Las causales de estas decisiones aún no han podido ser definidas con claridad, por cuanto ello requiere de una profundización en el análisis de cada uno de los casos señalados que no ha sido posible en virtud de la documentación a la que se ha tenido acceso.

El caso de la Chile-Argentina, luego Sociedad Ganadera Gente Grande, responde productivamente al mismo tipo de inversión tecnológica, manejo administrativo y utilización combinada de las superficies para invernada y veranada, que el resto de los grandes establecimientos que funcionaron en esos años en territorio neuquino, aunque dada la superficie concentrada en propiedad -recuérdese que fueron más de 400000 ha-, la magnitud de las inversiones superaba ampliamente a cualquier otra de las empresas que hayamos estudiado para el norte de la Patagonia argentina. La información obtenida de diversas fuentes permite señalar que, aun con las diferencias que la escala de producción, la disponibilidad de capital y el acceso a la información podían marcar, las grandes empresas establecidas en el territorio para la explotación ganadera -fueran estas sociedades anónimas chilenas, inglesas, argentinas o productores individuales-respondieron a una organización de la producción, una lógica de comercialización y un patrón de inversiones en las explotaciones que reconocen más similitudes que diferencias.

El presente trabajo abre sin duda interrogantes que aún no encuentran respuestas definitivas en función de las fuentes consultadas. Sin embargo, adquiere relevancia en la medida en que permite matizar de manera significativa versiones simplistas y de larga vigencia en la producción historiográfica argentina. El análisis de esta práctica implementada por sociedades chilenas en las primeras décadas del siglo XX en las áreas andinas patagónicas -aunque el caso analizado de manera puntual corresponde particularmente al territorio de Neuquén-, contribuye a mostrar otras formas de ocupación y puesta en producción de las tierras, así como mecanismos de vinculación social y económica que no responden a la clásica visión de un poblamiento del sur argentino exclusivamente proveniente del este, que acompañó una expansión de la ganadería lanar con destino al mercado atlántico por entonces en plena expansión. Por el contrario, esta investigación da cuenta de una ocupación y puesta en producción de las áreas cordilleranas que da continuidad, resignificándola, a la histórica vinculación que las sociedades indígenas de ambos lados de la cordillera habían mantenido por largo tiempo antes de la constitución de los respectivos Estados nacionales.

Asimismo, al analizar específicamente las inversiones chilenas en Neuquén y la constitución de sociedades anónimas con ese fin en el vecino país, el presente trabajo demuestra la existencia de una práctica que ya no puede considerarse exclusiva del extremo más austral del país -sur de 
Santa Cruz y Tierra del Fuego-, sino que representa un patrón de inversión común con presencia en la mayoría de los territorios patagónicos. Al mismo tiempo, la forma en que en el caso analizado -y en otros estudiados para el área neuquina- se produce la acumulación del patrimonio territorial, la puesta en producción ganadera y la articulación comercial, contribuye a complejizar la visión del funcionamiento socioeconómico regional y nacional, poniendo en discusión la llamada "marginalidad" de las áreas patagónicas respecto de la producción ganadera pampeana.

\section{FUENTES CONSULTADAS}

\section{Archivos}

AGN Archivo General de la Nación, Buenos Aires.

AHPN Archivo Histórico Provincial de Neuquén, Neuquén.

AHR Archivo Histórico Regional Cooperativa de Electricidad, San Carlos de Bariloche.

AHSCH Archivo Histórico de Santiago de Chile, Santiago de Chile.

AJLTN Archivo de la Justicia Letrada del Territorio de Neuquén, Neuquén.

BCRA Banco Central de la República Argentina, Buenos Aires.

DPCN Dirección Provincial de Catastro de Neuquén, Neuquén.

DPTN Dirección Provincial de Tierras de Neuquén, Neuquén.

MBNA Museo del Banco de la Nación Argentina, Buenos Aires.

RPCN Registro Público de Comercio de Neuquén, Neuquén.

\section{Hemerografía}

Buenos Aires Herald, Buenos Aires.

El Territorio, Neuquén.

La Cordillera, Neuquén.

La Nación, Buenos Aires.

\section{Bibliografía}

Anuario Sucesos. Guía general de Chile 1919-1920, año II, Valparaíso, E. Gómez y Cía., 1920.

BAndieri, Susana, "La cordillera de los Andes en el norte de la Patagonia o la frontera argentino-chilena como espacio social. Un estudio de caso", Estudios Fronterizos, Instituto de Investigaciones Sociales-Universidad Autónoma de Baja California, núm. 22, 1991, México, pp. 133-165. 
"Actividades económicas y modalidades de asentamiento" en SUSANA Bandieri, Orieta Favaro y Marta Morinelli, Historia de Neuquén, Buenos Aires, Plus Ultra, 1993.

"Áreas andinas y relaciones fronterizas: un ajuste de periodización" en Jorge Pinto Rodríguez, Araucanía y pampas: un mundo fronterizo en América del Sur, Temuco, Universidad de la Frontera, 1996, pp. 175-200.

"Neuquén en debate. Acerca de la continuidad y ruptura del circuito mercantil andino”, Anuario IEHS, Universidad Nacional del Centro, núm. 14, 1999, Tandil. "Neuquén: grupos de poder, estrategias de acumulación y prácticas políticas”, Anuario IEHS, Universidad Nacional del Centro, núm. 15, 2000, Tandil. "Estado nacional, frontera y relaciones fronterizas en los Andes norpatagónicos: continuidades y rupturas" en SusANA BANDIERI, Cruzando la cordillera... La frontera argentino-chilena como espacio social, Neuquén, Centro de Estudios de Historia Regional-Universidad Nacional del Comahue, 2001, pp. 345-374 (2a. edición, Centro de Estudios de Historia Regional-Universidad Nacional del Comahue, de 2005).

BANDIERI, SUSANA et al., "Los propietarios de la nueva frontera: tenencia de la tierra y estructuras de poder. Primeros avances", Revista de Historia, Universidad Nacional del Comahue, vol. 5, 1995, pp. 133-152.

Bandieri, Susana y Graciela Blanco, "Propietarios y ganaderos chilenos en Neuquén: una particular estrategia de inversión (fines del siglo XIX y comienzos del xx)”, Estudios Trasandinos, Asociación Chileno Argentina de Estudios Históricos e Integración Cultural, año 2, vol. 2, 1998, pp. 43-74.

"Política de tierras en los territorios nacionales. Entre la norma y la práctica” en Graciela Blanco y Guillermo Banzato, La cuestión de la tierra pública en Argentina. A 90 años de la obra de Miguel Ángel Cárcano, Rosario, Prohistoria Ediciones, 2009, pp. 163-199.

Barbería, Elsa Mabel, Los dueños de la tierra en la Patagonia austral, 1880-1920, Río Gallegos, Universidad Nacional de la Patagonia Austral, 1995.

BARbero, MARÍA InÉs, "La historia de empresas en la Argentina: trayectoria y temas en debate en las últimas dos décadas" en Jorge Gelman, La historia económica argentina en la encrucijada. Balances y perspectivas, Buenos Aires, Asociación Argentina de Historia Económica/Prometeo Libros, 2006, pp. 153-154.

Bauer, Arnold, La sociedad rural chilena. Desde la conquista española hasta nuestros días, Santiago de Chile, Andrés Bello, 1994.

BengoA, José, Haciendas y campesinos. Historia social de la agricultura chilena, Santiago de Chile, Sur, 1990, t. II.

Biaus, Rodolfo M. y Óscar F. Maldonado, Álbum guía comercial de Río Negro y Neuquén, Buenos Aires, Editorial Argentina de Publicidad, 1929.

Blackpaine, Joseph, Los alemanes en el sur de Chile, Santiago de Chile, s. e., 1994.

Blanco, Graciela, "El Estado argentino en el desarrollo ganadero de Patagonia: la distribución de la tierra y los inversores privados en Neuquén a principios del siglo 
XX” en Marta Valencia y Sonia Regina de Mendonça, Brasil e Argentina. Estado, agricultura e empresarios, Río de Janeiro, Vicio de Lectura/Universidad Nacional de La Plata, 2001, pp. 165-199.

, "Tierra, ganado y empresas en Neuquén: poder público e inversores privados en Neuquén, 1880-1970", tesis doctoral, Universidad Nacional de La Plata, 2002.

BORGOÑO, VÍCTOR, La colonización y la constitución de la propiedad en las provincias del sur. Sexta memoria del director de la oficina de mensuras de tierras, Santiago de Chile, s. e., 1913.

Brunswig de Bamberg, María, Allá en la Patagonia. La vida de una mujer en una tierra inhóspita, Buenos Aires, Javier Vergara Editor, 1995.

Chamorro, Claudio, Bajo el cielo austral, Santiago de Chile, Imprenta y Litografía La Ilustración, 1936, vol. 1.

DestéfFaniz, CARolina, "Los procesos de conformación de las burguesías regionales de la norpatagonia argentina y el sur chileno entre finales del siglo XIX y mediados del Xx”, informe de investigación, Neuquén, Universidad Nacional del Comahue, 2000, pp. 118-119 (mimeo.).

EDELMAN, ÁNGEL, Guía comercial Edelman. Información sobre ganadería, agricultura, comercio, industria, minería, turismo, autoridades, servicios públicos, etc. Territorio del Neuquén y parte de Río Negro, Buenos Aires, Talleres Gráficos M. Neumann y Cía., 1924.

Empresa Franco Argentina Editora, Guía de información comercial e industrial de Chile. Comercio, industria, agricultura, salitre y minería, Santiago, Imprenta Sudamericana, 1913.

EsPejo, Rodemil, Guí ilustrada, industrial y comercial, 1907-1908, Valparaíso, Westcott y Co., 1908.

Martinic Berós, Mateo, Magallanes, sintesis de tierra y gentes, Buenos Aires, Francisco de Aguirre, 1972.

Míguez, Eduardo José, Las tierras de los ingleses en la Argentina, 1870-1914, Buenos Aires, Editorial de Belgrano, 1985.

Ministerio de Agricultura, Memoria de la inspección general de colonización e inmigración correspondiente al año 1907, Santiago de Chile, Imprenta Universitaria, 1908.

República De Chile, Quinta Memoria del director de la Oficina de Mensura de Tierras al señor ministro de Colonización, 1912, Santiago de Chile, Imprenta Universitaria, 1912.

VAREla, Gladys y Ana María Bisset, “Guerras, alianzas, arreos y caravanas. Los indios de Neuquén en la etapa colonial” en Susana Bandieri, Orietta Favaro y Marta Morinelli, Historia del Neuquén, Buenos Aires, Plus Ultra, 1993, cap. II.

Verniory, Gustave, Diez años en la Araucanía, 1889-1899, Santiago de Chile, Universidad de Chile, 1975.

Villalobos, Sergio, Origen y ascenso de la burguesía chilena, Santiago de Chile, Editorial Universitaria, 2a. ed., 1988.

Zingoni, Celia, “Sucedió en Catan Lil, 1897-1922”, biografía, Buenos Aires (mimeo.). 